\title{
A Return on Our Experience of Modeling a Service-oriented Organization in a Service Cartography
}

\author{
Gorica Tapandjieva ${ }^{1}$, Giorgio Anastopoulos ${ }^{2}$, Georgios Piskas ${ }^{1}$, Alain \\ Wegmann $^{1}$ \\ 1 École Polytechnique Fédérale de Lausanne, \\ Systemic Modeling Laboratory LAMS \\ Station 14, CH-1015 Lausanne, Switzerland \\ \{gorica.tapandjieva, georgios.piskas, alain.wegmann\}@epfl.ch, \\ WWW home page: http://lams.epfl.ch/ \\ 2 École Polytechnique Fédérale de Lausanne, \\ Information Systems SI \\ Station 14, CH-1015 Lausanne, Switzerland \\ giorgio.anastopoulos@epfl.ch, \\ WWW home page: http://vpsi.epfl.ch
}

\begin{abstract}
We present a longitudinal project using action design research, which is a four-year collaboration between two EPFL entities: The research Laboratory for Systemic Modeling (LAMS) and EPFL's IT department, called the VPSI. During that time the VPSI was going through a transformation into a service-oriented organization. The research project began as an open-ended modeling of some of the VPSI processes. It slowly matured into the design and development of a visualization tool we call service cartography. During this research, we learned that, to successfully apply service-orientation, focusing purely on IT architecture and end-customer value is not enough. Attention must be given to the exchange of internal services between the service organization members and their alignment with the services expected by the external stakeholders. In this paper we present the evolution of (1) our understanding of what services are, and (2) our conceptualization of how the service cartography facilitates the service-oriented thinking.
\end{abstract}

Key words: action design research, service-orientation, service cartography, SEAM, enterprise architecture

\section{Introduction}

The IT department of EPFL, called the VPSI for Vice Presidency of Information Systems (SI in French), provides IT infrastructure and development services to the entire EPFL community. Beginning around 2012, the IT department of

The final publication is available at Springer via http://dx.doi.org/10.1007/978-3-319-56925-3_19

Presented at the 8th International Conference on Exploring Service Science, IESS 1.7,

Sapienza University, Rome, Italy, May 24-26, 2017 
EPFL began to transform from a traditional IT organization, developing applications and maintaining infrastructure, into a so-called service organization as envisioned by frameworks such as the Information Technology Infrastructure Library (ITIL) 1, 2. An EPFL research laboratory, called LAMS, collaborated with the VPSI during the transformation project. LAMS specializes in Enterprise Architecture research. LAMS provided methodological advice to the VPSI members while improving its methods and publishing the results [3, 4, 5, 6, 7]. The first author began her involvement in this project by attempting to model business processes that support specific services offered by the VPSI. Gradually this involvement shifted to the mapping of services and their dependencies in an interactive tool that is called a service cartography.

Collaborating with the VPSI members, the LAMS researchers became aware that there is lack of clear guidelines: (1) to manage the internal service exchange and (2) to align the internal services with the VPSI's external stakeholders' expectations. The existing service management frameworks, such as ITIL 1], convey a clear vision of services, but they only give abstract guidelines concerning the implementation of this vision. For example, ITIL defines peoples' roles with different responsibilities in service management, but it does not provide information on how these roles collaborate, i.e., exchange services. Accordingly, the researchers learned that to apply service-orientation, focusing purely on IT architecture and end-customers is not enough.

The concept of a service is not new [8]. In the past two decades, services have been researched in the domains of service-oriented thinking [9], servicedominant logic [10, service systems [11, servitization [12, service-oriented architecture [13, and others. Most research on services "focuses on the interaction between the firm and the customer" [14, but an open question still remains: How do members of a service organization collaborate in the implementation of a certain service?

We believe that successful service-orientation is characterized by empowering employees to collaborate by exchanging services and aligning the results of this collaboration with the expectations of external stakeholders. Employees' work includes responsibilities in a given context, as well as services they use and they provide to other employees, systems, applications, organizations and end-users. Our ongoing efforts are towards designing and building a service cartography tool. It is envisioned that in this tool, the VPSI members will store and visualize the services exchanged and resources used, and by doing so, they will build a shared understanding of the internal collaboration.

This project can be categorized as action research because of its duration (four years) and the active operational role assumed by the researchers 15, 16. In addition, the research output is a designed artifact, namely the service cartography tool, which makes the project compatible with design-science frameworks [17. The research method we use is action design research (ADR) 18.

In Section 2 we give details of our research method. We describe the context of our ADR project, as well as our project iterations in Section 3. In Section 4. we explain the limitations and challenges researchers face when conducting an 
action-research project of this magnitude. In Section 5 we list the related work, and in Section 6 we present our conclusions.

\section{Research Method}

\section{Action Research}

We believe that "knowledge is created through transformation of experience" 19. As experience is gained by doing, we focus more "on what practitioners do, rather on what they say they do" [16. The research undertaken in real organizational context, aiming to solve immediate problem situation in collaboration with practitioners is called action research. As described by Avison et al. in [16]., "in action research, the researcher wants to try out a theory with practitioners in real situations, gain feedback from this experience, modify the theory as a result of this feedback, and try it again."

Introduced by Kurt Lewin in 1946, action research is social research combining "generation of theory with changing the social system through the researcher acting on or in the social system" [20. Patton [21] has categorized action research as "action-oriented, problem-solving research", with informal data collection and research publications different from those in basic and applied research. For example, there are a few academic publications on our collaboration with the VPSI 3, 4, 5, 6, 7, whereas we have produced many informal and internally circulated documents.

Conducting action research in the context of investigating information systems is not new. For example, Baskerville published a tutorial on an action research of information systems [22] and Checkland's soft systems methodology [15] is rooted in action research.

By using action research, we extend our knowledge by solving specific problems that we identify at the VPSI.

\section{Design Research}

In his book, "The Sciences of the Artificial" 23, Herbert A. Simon set the foundations for design methodologies relevant to various disciplines, including design science in IS. Looking through the design lens, the output of our research, the service cartography tool, is "a purposeful IT artifact created to address an important organizational problem" [17. This puts our research efforts in Hevner et al.'s framework for IS design-science research.

But Sein et al. [18, point out that "traditional design science does not fully recognize the role of organizational context in shaping the design, as well as shaping the deployed artifact". However, they also mention a few researchers that have "a view of artifacts as emergent from organizational context", and they propose a design research method that does not separate the IT artifacts from the interaction with the organizational context. Their method is called action design research (ADR) and we find it best fits our approach for IS research. 


\section{Action Design Research}

Action design research is a research method that has four stages (see Fig. 1), where each stage contains a set of principles. We briefly explain the stages, without focusing on the principles:

1. Problem Formulation is a stage in which researchers identify, articulate and scope a problem inspired by practitioners, researchers, end-users, technologies or prior research.

2. Building, Intervention and Evaluation (BIE) is a stage that is carried out as an iterative process interweaving "the building of an IT artifact, intervention in the organization and evaluation" [18].

3. Reflection and Learning occurs in parallel with the first two stages: researchers reflect on the problem formulated, and on the theories and tools chosen to develop a particular solution. The learning from this reflection leads to a refined problem formulation and solution, as both researchers and practitioners gain a better understanding of the emerging artifact.

4. Formalization of Learning is the most challenging stage, as the learning from the ADR project should result with generalized solution concepts for a class of field problems.

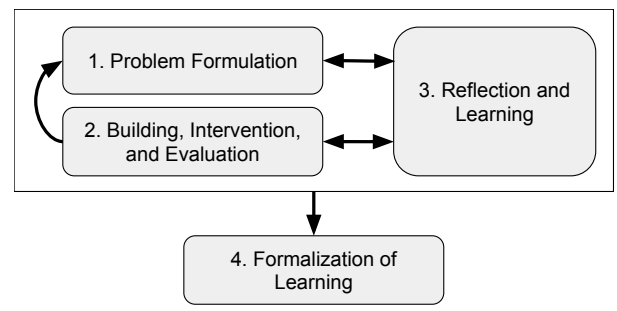

Fig. 1. Action design research method stages, adapted from [18].

In the following section, we illustrate how we applied ADR in our research project conducted at EPFL.

\section{Service Cartography: Research Project in Collaboration with the EPFL Information Systems Department}

The VPSI provides approximately 100 IT services to around 14,000 EPFL members, of which in 2015 [24] around: 3,000 are researchers and lecturers, 300 are professors, 10,000 are students, 5,000 are employees, including administrative staff, IT experts and others. Some of these members have dual roles (for example professors, researchers and lecturers are also employees). Besides EPFL members, the VPSI also serves many more visitors and the general public. The 
marketing term "segment" is adopted to designate these separate groups of customers with different needs.

The VPSI's transformation into a service-oriented organization introduced a challenge to the internal organization. In parallel, to optimize the creation, management and operation of services, the VPSI developed a service strategy. The service strategy defines ways of collaborating in the service-oriented organization. This strategy also explains why services are needed and defines roles the VPSI members have in implementing these services.

The following subsections present the research collaboration with the VPSI through the ADR lens. Figure 2 depicts three major Building, Intervention and Evaluation (BIE) iterations, each lasting more than a year, and each having finely-grained, shorter iterations. As described in [18, "during BIE, the problem and the artifact are continually evaluated". Consequently, in each major iteration, the ADR team members gained better understanding of the problem and they tried to reformulate it. The artifact was updated in parallel to reflect the changing problem addressed.

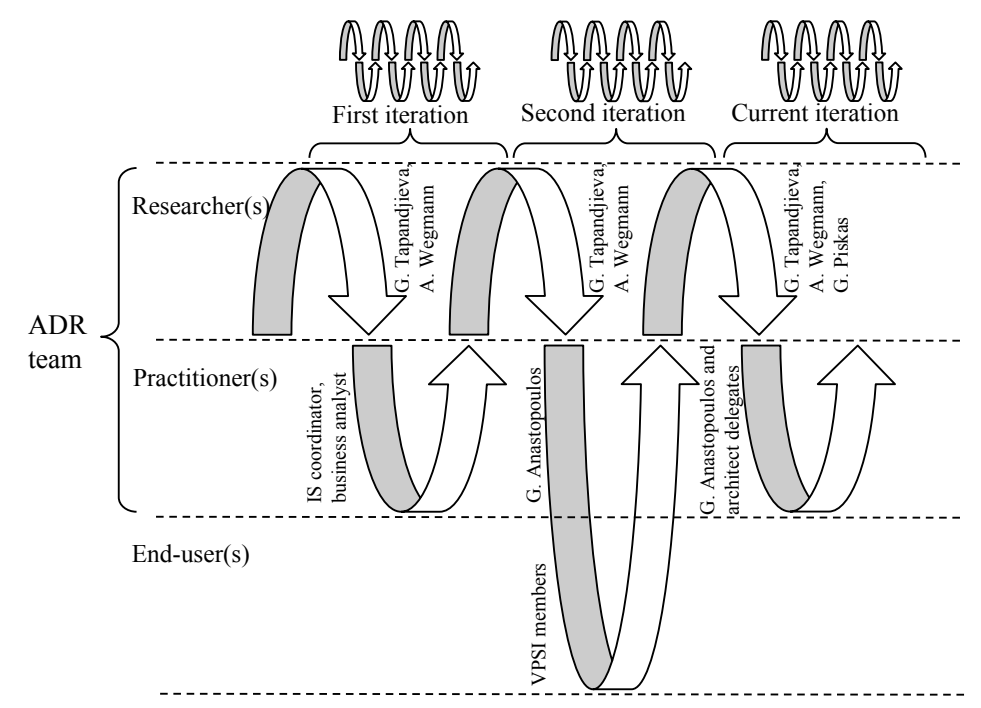

Fig. 2. Three major Building, Intervention and Evaluation (BIE) iterations for an IT-Dominant ADR project at EPFL's IT department, called the VPSI.

Due to the informal collaboration with the VPSI, in every major iteration, different practitioners belong to the ADR team. As a consequence, specific roles and responsibilities of the ADR team members are not defined. BIE iterations are conducted in a semi-structured manner where researchers rely on their observations and discussions with practitioners. 


\subsection{First iteration}

Problem Formulation In the beginning of the collaboration with the VPSI, researchers identified that the VPSI management needed to build and communicate a common view of the service-oriented enterprise architecture in the context of the ongoing strategy formulation 3 .

Building, Intervention and Evaluation During the first iteration, researchers focused on modeling the architecture of several VPSI business processes. This iteration was used to understand and visualize the internal organization of resources and people in different roles. The idea was to build a map of IT resources, services, EPFL employees, users, external partners, protocols. As defined in [25], maps are "graphic representations that facilitate a spatial understanding of things, concepts, conditions, processes, or events in the human world". Cartography is the practice of making maps, therefore, the artifact was named an IT cartography. The design of the IT cartography was based on SEAM [26] conceptualization. SEAM is a service-oriented framework developed at LAMS [27.

To create the IT cartography artifact, the ADR team members chose a commercial tool called SOLU-QIQ 28] in which the researchers implemented the SEAM meta-model [5]. Figure 3 shows the cartography output during this iteration.

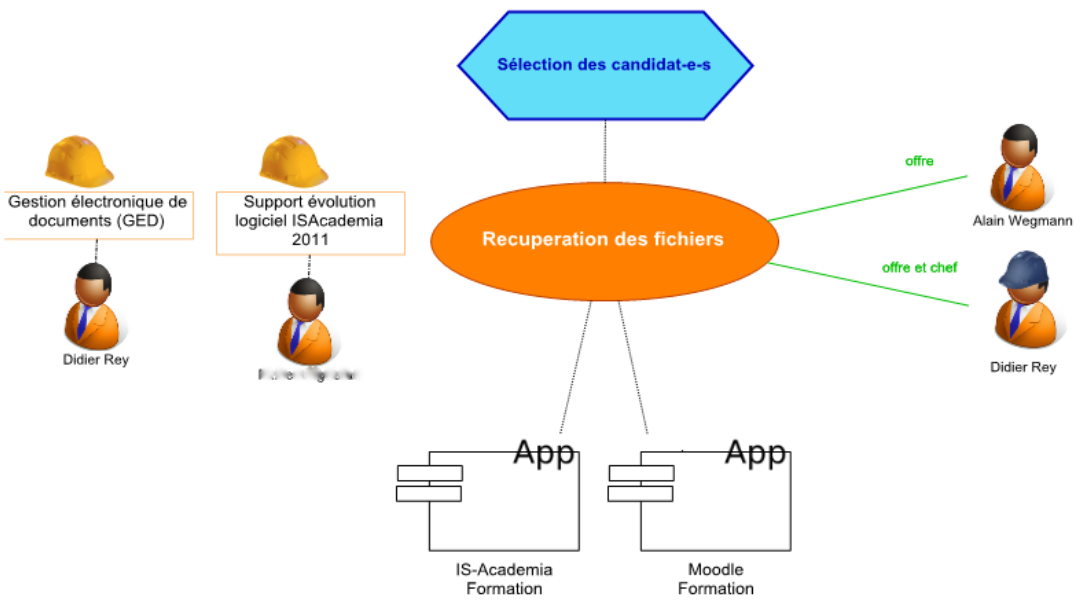

Fig. 3. IT cartography output, taken from [3], showing people and applications involved in one service implementation, with the process that consumes that service.

In this iteration, all decisions were made during frequent meetings and semistructured interviews among researchers and two VPSI members (belonging to the ADR team), the EPFL's IS coordinator and a business analyst. The re- 
searchers also occasionally attended meetings with other VPSI members, to better relate to the problems VPSI was solving.

Reflection and Learning As EPFL employees, the researchers used VPSI services on a daily basis, enabling themselves to experience first-hand the value services bring to the customer. The researchers also related their experience to the industry and academic service approaches. Moreover, the frequent discussions with the IS coordinator and the business analyst crystallized the understanding of services. In these discussions, all ADR team members made SEAM sketches to conceptualize their learning of services. The progress made was partly attributed to the SEAM sketches made.

At the end of the first iteration, the IT cartography showed only one service implementation per view, with a different notation from the usual SEAM notation. The different notation caused confusion among ADR team members, as the cartography did not represent the SEAM conceptualization from the discussions.

As a result of the reflection,

- the ADR team decided to apply the standard SEAM notation, and

- the IT cartography was spontaneously referred to as service cartography.

Finally, the service cartography built contained only a few example services, hence the ADR team believed it was not ready to be shared with all VPSI members.

\subsection{Second iteration}

Problem Formulation The ADR team gained a better understanding of the problem and they had ideas on how to improve the service cartography. The researchers found that there was no need to reformulate the problem after the first iteration.

Building, Intervention and Evaluation At the start of this iteration, the second author of this paper, joined the VPSI, as the head of IS architecture. From the moment he joined, on top of his VPSI work, he became a member of the ADR team. In the first few months, the collaboration mainly involved knowledge transfer concerning SEAM, SOLU-QIQ and EPFL services in general. Afterwards, he became the main service cartography user, designer and developer. All ADR team members collaborated on designing the cartography overview page (see Fig. 4(a) and the navigation between the detailed views. The second author was also the main advocate for having the standard SEAM notation in the service cartography. He succeeded in implementing a notation similar to the standard SEAM notation (see Fig. 4(b)]. The first and second author conducted several interviews with other EPFL members, and they populated the service cartography with the information gathered. Subsequently, the head of IS architecture independently updated the service cartography, and after having the information for many services, he made the tool available to all VPSI members. In the following months, the ADR team observed that the VPSI 
members did not use the service cartography, despite having the tool at their disposal.

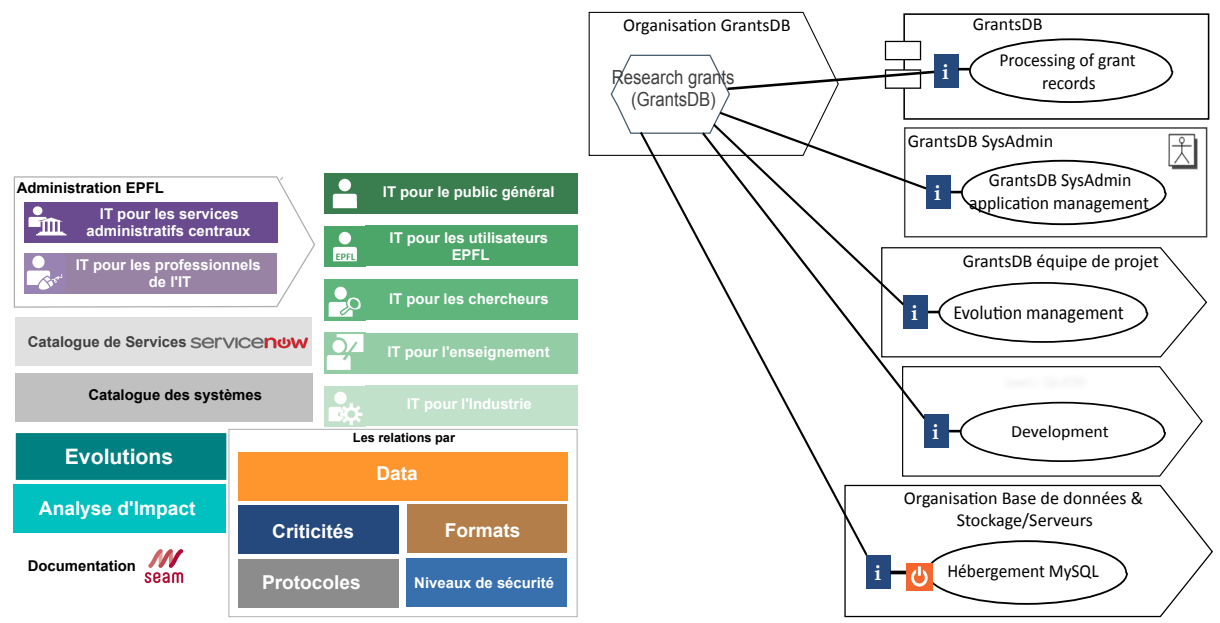

(a) Starting overview

(b) One level service implementation view

Fig. 4. The service cartography developed in the second iteration

The evaluation in this iteration was marked by a contextual inquiry [29] the first author conducted with a service manager. In this one-month contextual inquiry, the first author developed a master/apprentice relationship where the service manager was the master. The idea behind a contextual inquiry is to discover actions as they occur, to allow the service manager to talk about his work as it happens, and not to ask structured questions as in a traditional interview scenario 29]. The goal of this evaluation approach in the ADR project was to learn more about the daily work of a service manager and understand why the service managers did not consult the service cartography.

During the contextual inquiry, some observed activities of the service manager were (1) maintaining relationships with end-users and people involved in the service implementation, and (2) producing and updating the service documentation such as service description, service architecture, service change requests, and service knowledge base. The output views from the service cartography could be included in various service documentations, but navigating to the specific view of the service of interest was almost impossible.

Reflection and Learning With the introduction of service orientation, the VPSI members are expected to separate the "service offering" and the "service implementation". The service offering is the end-customer's value-added level, whereas the service implementation is not visible to the end-customer and it represents the internal services and resources used to develop the offering. This separation is perceived as the major benefit of service-orientation and it focuses 
solely on the end-customer value. But what about the values of VPSI employees and other internal customers?

From the contextual inquiry, we learned that in the service documentation, service managers communicate their internal service-exchange. In this documentation, service managers describe the organization of the collaboration they have with other internal and external people, and the resources they use. The service cartography stores service-to-service, service-to-segment and service-to-person relationships within a defined collaboration context. The ADR team also became aware that the web pages with this information were difficult to find, were displayed in predefined views (see Fig. 4(b) and could not be changed. By observing these pitfalls, the ADR team members realized they did not understand the needs of the users and the constraints imposed by the SOLU-QIQ tool. In addition, the maps generated with SOLU-QIQ were static, so the team decided

1. To stop using SOLU-QIQ and design a new employee-centric tool. The new tool should allow the VPSI employees to dynamically build their own service map, in order to fit exactly the needs of the employee at a given point in time for a specific purpose.

2. To initiate a frequent collaboration with one specific role, the architect delegate, in order to capture role-specific use cases.

\subsection{Current iteration}

Problem Formulation How can an employee of a service-oriented organization visualize and communicate her work? Based on ADR team's observations, an employee's work includes exchanging internal services and the value these services provide to her external stakeholders (customers, suppliers).

Building, Intervention and Evaluation In the current iteration, the ADR team develops a new service cartography that enables VPSI members to communicate the internal service-exchange. The new service cartography is user centric. Instead of navigating between predefined views, the VPSI members search for the services or systems and interactively build service maps they need, starting from an empty canvas. Also, the VPSI members are independent from one another while dynamically building their map. The service maps they create can then be saved, exported and shared with other EPFL members. In addition, there is no restriction on the details shown: the map can show multiple service levels, starting from the lowest service level (e.g., network), all the way to the business services, and end-user level. For example, Fig. 5 shows two service levels, and it can be expanded. Furthermore, the service cartography has links to EPFL's service catalog and EPFL people's directory. Additional features include a few predefined overviews:

- Aggregate overview relationships among all services with their context (not shown in this paper).

- The cropped overview in Fig. 6(a) shows collaboration for a specific service, where people are grouped around a service on which they worked at least once. 


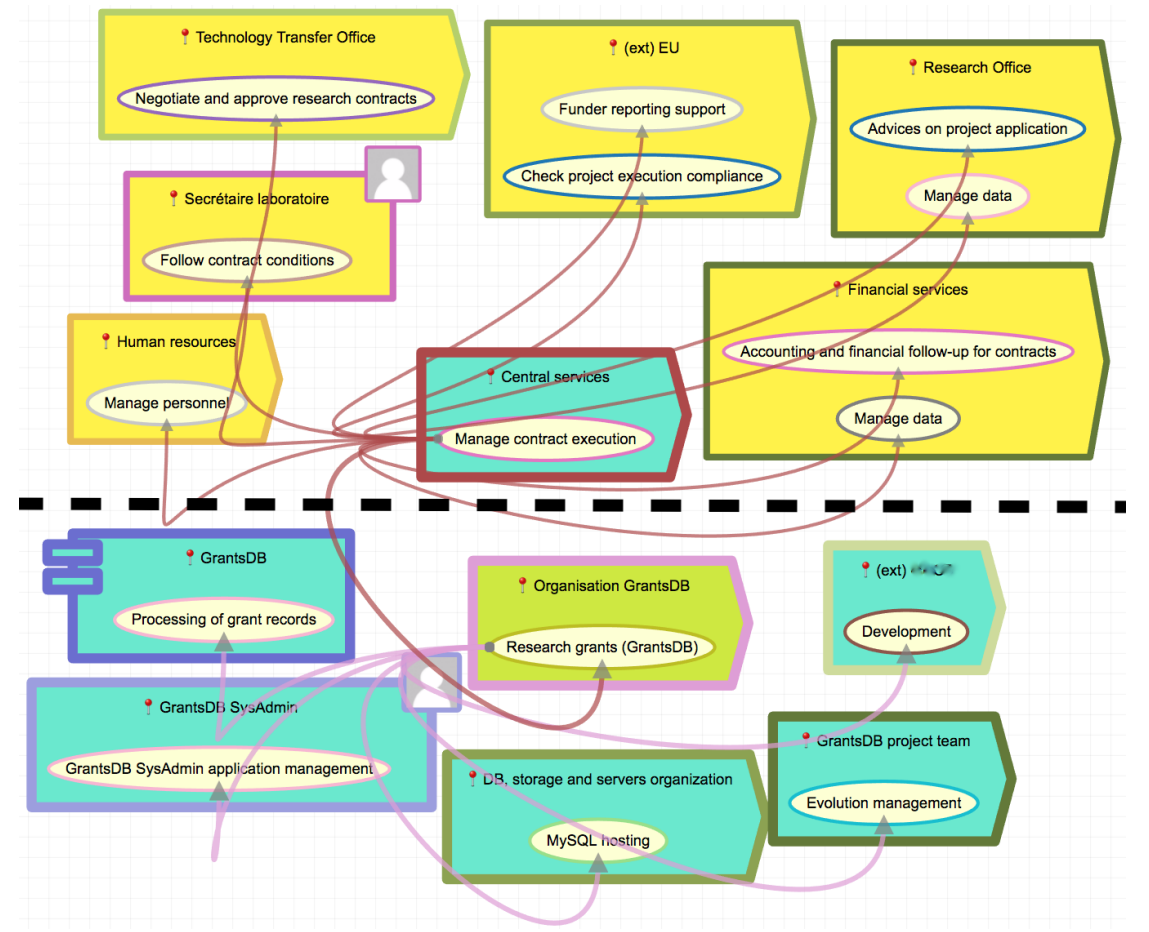

Fig. 5. The service cartography visualization tool in which users build their own map. The figure shows two service levels distinguished by the different colors of relationships. The service level of Fig. 4(b) is depicted below the dashed line.

- Fig. 6(b) shows the opposite: the employee is visualized in the center of all services on which he worked at least once.

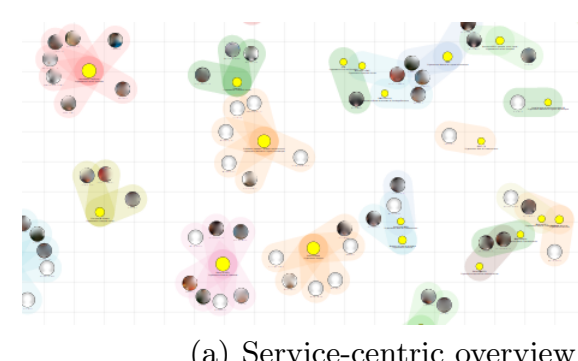

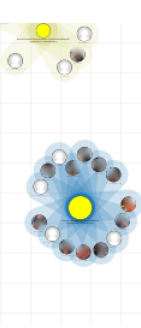

(a) Service-centric overview

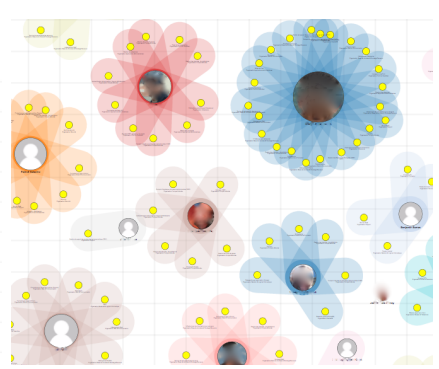

(b) Person-centric overview

Fig. 6. Overviews in the service cartography 
In this iteration, the development of the service cartography with all new features is done by a master's student, who is the third author. In addition, ADR researchers initiate a closer collaboration with the VPSI members who have an architect delegate role. An architect delegate is a specialist in one architectural domain, such as network, security and databases. The architect delegates and the head of IS architecture, form the architecture body that ensures "the coherence and efficiency of EPFLs information system" 30. The researchers join the monthly architecture meetings to get regular feedback, ideas and requests for new features. They should develop a more intensive individual collaboration with each architect delegate, in order to better elicit all service cartography use cases in their context.

Reflection and Learning In the previous two iterations, the researchers were focused on the design rather than on the action in the organization. By including the architect delegates in the early stages of the service cartography redesign, researchers hope to avoid some of the mistakes presented in [31, such as building a system that employees are reluctant to use.

After all project iterations, the researchers stabilized the formulation of the problem they are solving. They are currently reflecting on other approaches, both in academia and industry, that emphasize the internal service and value exchange. The importance of the internal service exchange is already indicated by Vargo and Lusch in [10. Their second foundational premise states that without direct interaction with the end customer, employees lose sense of the internal service exchange among themselves, which leads to ignoring "quality and both internal and external customers" [10].

\section{Limitations and Challenges}

The emergent knowledge from an experience is "a knowledge which is contingent on the particular situation" 20] of a given moment (in this ADR project). All decisions taken "are subject to reexamination and reformulation upon entering every new research situation" 20]. The researchers cannot provide measurements for the improvements our service cartography brought to the VPSI and this paper only presents observations.

Most of the challenges faced in an ADR project are related to the dual role that the researchers and practitioners have. It is important for the practitioners to manage politics well, in order to "have a future in the organization when the research is completed" 32 .

Involving VPSI members in this project requires managing relationships and negotiation with the employees and their supervisors. Sometimes the researchers encountered delays in securing the involvement of the VPSI members, thus making the time horizon of the ADR project unpredictable. 


\section{Related Work}

The service cartography artifact is inspired by the field of enterprise architecture (EA). The objective of EA is to capture "the essentials of the business, IT and its evolution" in a holistic view 33. Some EA authors use the metaphor of city planing and urbanization [34, and others use the metaphor of building a house [35. The strong association with IT resources is a limitation of most EA approaches, such as the Zachmann framework [35, the IT4IT Reference Architecture [36] and TOGAF [37. These approaches do not conceptualize the employees, employees' roles, and the contexts in which employees work; and they do not have a coherent representation of all organizational levels. For this reason the service cartography visualization is based on SEAM models, where people and their services can be modeled at any level of the hierarchy and seen in a concrete context.

The ADR team's goal is to visualize the relationships among services that exist in an organization. There are a few commercial tools [38, 39] that automatically map service dependencies. These tools discover the technical details of services and application deployments, such as the communication endpoint, the address of the server or virtual machine where a service runs. They operate on the level of configuration items and address IT administrator's needs in finding a root-cause of a technical problem. Consequently, people's explicit responsibilities and collaborations for a specific service are not visualized, whereas we visualize all relationships that show collaboration among people, applications and technologies, all the way to the end user. These tools, however, can provide aggregate data for technical services, that can then be integrated in the service cartography visualizations.

Mega's HOPEX [40] and Link Consulting's EAMS 41] are commercial tools close to our service cartography. These tools are an Enterprise Architecture Management System (EAMS). Both of them are compatible with TOGAF and the second one has the feature to show the evolution of the models over time. The main difference with our tool is the focus on services and relationships among employees. Nevertheless, we get inspired by their features.

\section{Conclusions}

In this paper we have presented our experience of conducting a four-year ADR project of building a service cartography artifact, the directions taken and difficulties encountered. The researchers' activities and what they learned in the ADR project are presented in three major iterations. In the first iteration, the researchers tackled the architectural challenges, and the cartography tool was designed to communicate only the architectural perspective. In the second iteration, the ADR team populated the cartography tool with information gathered from interviews and made the output available to all VPSI members. Due to the static nature of the cartography tool, the VPSI members did not use it. 
Thanks to the intensive collaboration and reflection on service orientation, all the ADR team members are able to see their work as an internal serviceexchange. As the ADR team members did not need to rely on any tool, they concluded that it is tool agnostic to maintain a sense of service exchange in their work. But not all VPSI members can, or would like to, be included in an ADR project. Nevertheless, due to the lack, in both industry and academia, of concrete guidelines for managing internal collaboration in a service-oriented organization, the ADR team observed that the VPSI members still need a flexible and dynamic tool to visualize their services and to communicate about their collaborations. The researchers maintain their belief that by using the service cartography, VPSI members could (1) build a shared understanding of existing internal/external services, and (2) organize discussions in meetings, hence (3) adopt a serviceoriented way of thinking.

\section{References}

1. Cartlidge, A., Hanna, A., Rudd, C., Macfarlane, I., Windebank, J., Rance, S.: An Introductory Overview of ITIL v3. The UK Chapter of the itSMF (2007)

2. Information Technology Infrastructure Library, https://www.axelos.com/bestpractice-solutions/itil

3. Tapandjieva, G., Marchetti, D.R., Rychkova, I., Wegmann, A.: Towards the Definition, Implementation and Communication of an IT Strategy: the Case of IT Strategy at EPFL. In: International Conference on Advanced Information Systems Engineering. pp. 99-110. Springer (2013)

4. Popescu, G., Tapandjieva, G., Wegmann, A.: Business and IT Design with SEAM: An Illustration with the $\mathrm{PhD}$ Hiring Process at École Polytechnique Fédérale de Lausanne. In: 2013 IEEE International Conference on Systems, Man, and Cybernetics. pp. 1938-1943. IEEE (2013)

5. Tapandjieva, G., Wegmann, A.: Specification and Implementation of a Meta-model for Information Systems Cartography. In: Proceedings of the CAiSE2014 Forum at the 26th International Conference on Advanced Information Systems Engineering (CAiSE). vol. 1164, pp. 113-120. CEUR-WS. org (2014)

6. Tapandjieva, G., Gopal, A., Grossan, M., Wegmann, A.: Patterns for Value-Added Services Illustrated with SEAM. In: 5th International Workshop on Models and Model-driven Methods for Service Engineering (3M4SE '14), as part of the Enterprise Computing Conference (EDOC) 2014 (2014)

7. Tapandjieva, G., Regev, G., Wegmann, A.: SLA: to Sign or Not to Sign. In: Proceedings of the 2nd International Workshop on Socio-Technical Perspective in IS Development (STPIS), a CAiSE '16 workshop. vol. 1604, pp. 15-24 (2016)

8. Zeithaml, V.A., Parasuraman, A., Berry, L.L.: Problems and Strategies in Services Marketing. The Journal of Marketing pp. 33-46 (1985)

9. Demirkan, H., Kauffman, R.J., Vayghan, J.A., Fill, H.G., Karagiannis, D., Maglio, P.P.: Service-oriented Technology and Management: Perspectives on Research and Practice for the Coming Decade. Electronic Commerce Research and Applications $7(4), 356-376$ (2009)

10. Vargo, S.L., Lusch, R.F.: Evolving to a New Dominant Logic for Marketing. Journal of marketing 68(1), 1-17 (2004) 
11. Spohrer, J., Maglio, P.P., Bailey, J., Gruhl, D.: Steps Toward a Science of Service Systems. Computer 40(1), 71-77 (2007)

12. Vandermerwe, S., Rada, J.: Servitization of Business: Adding Value by Adding Services. European Management Journal 6(4), 314-324 (1988)

13. Krafzig, D., Banke, K., Slama, D.: Enterprise SOA: Service-Oriented Architecture Best Practices. Prentice Hall Professional (2005)

14. Lusch, R.F., Vargo, S.L., Wessels, G.: Toward a Conceptual Foundation for Service Science: Contributions from Service-dominant Logic. IBM Systems Journal 47(1), 5-14 (2008)

15. Checkland, P., Holwell, S.: Information, Systems and Information Systems: Making Sense of the Field. Wiley, Chichester; New York (1997)

16. Avison, D.E., Lau, F., Myers, M.D., Nielsen, P.A.: Action Research. Communications of the ACM 42(1), 94-97 (1999)

17. Hevner, A., March, S., Park, J., Ram, S.: Design Science in Information Systems Research. MIS quarterly 28(1), 75-105 (2004)

18. Sein, M.K., Henfridsson, O., Purao, S., Rossi, M., Lindgren, R.: Action Design Research. MIS Quarterly 35(1), 37-56 (2011)

19. Kolb, D.A.: Experiential Learning: Experience as the Source of Learning and Development. FT press (2014)

20. Susman, G.I., Evered, R.D.: An Assessment of the Scientific Merits of Action Research. Administrative Science Quarterly pp. 582-603 (1978)

21. Patton, M.Q.: Qualitative Evaluation and Research Methods. SAGE Publications, inc (1990)

22. Baskerville, R.L.: Investigating Information Systems with Action Research. Communications of the AIS 2(3es), 4 (1999)

23. Simon, H.A.: The Sciences of the Artificial. MIT Press (1996)

24. EPFL Annual Report 2015, http://information.epfl.ch/annual_report

25. Woodward, D., Harley, J.B.: The History of Cartography. Volume 1: Cartography in Prehistoric, Ancient, and Medieval Europe and the Mediterranean (1987)

26. Wegmann, A.: On the Systemic Enterprise Architecture Methodology (SEAM). In: 5th International Conference on Enterprise Information Systems (ICEIS 2003) (2003)

27. SEAM, http://lams.epfl.ch/seam/

28. SOLU-QIQ - Accueil, https://www.soluqiq.fr/

29. Beyer, H.R., Holtzblatt, K.: Apprenticing with the Customer. Communications of the ACM 38(5), 45-52 (1995)

30. Architecture - EPFL-SI, http://informationsystem.epfl.ch/architectureEN

31. Markus, M.L., Keil, M.: If We Build It, They Will Come: Designing Information Systems That People Want to Use. Sloan Management Review 35(4), 11 (1994)

32. Coghlan, D., Brannick, T.: Doing Action Research in Your Own Organization. Sage (2014)

33. Lankhorst, M.: Enterprise Architecture at Work: Modelling, Communication and Analysis. Springer (2009)

34. Longépé, C.: The Enterprise Architecture IT Project: the Urbanisation Paradigm. Butterworth-Heinemann (2003)

35. Zachman, J.: A Framework for Information Systems Architecture. IBM systems journal 26(3), 276-292 (1987)

36. IT4IT Reference Architecture, Version 2.0, http://pubs.opengroup.org/it4it/refarch20/index.html

37. Josey, A.: TOGAF® Version 9.1-A Pocket Guide. Van Haren (2011) 
38. ServiceNow Wiki: Using a Next Generation BSM Map, http://wiki.servicenow.com /index.php?title=Using_a_Next_Generation_BSM_Map

39. Service Map in Operations Management Suite (OMS), https://docs.microsoft.com/en-us/azure/operations-managementsuite/operations-management-suite-service-map

40. HOPEX - MEGA, http://www.mega.com/en/product/hopex

41. EAMS homepage, http://www.linkconsulting.com/eams/ 